\title{
REVIEW OF ENERGY MANAGEMENT AND ENERGY AUDIT IN INDIA
}

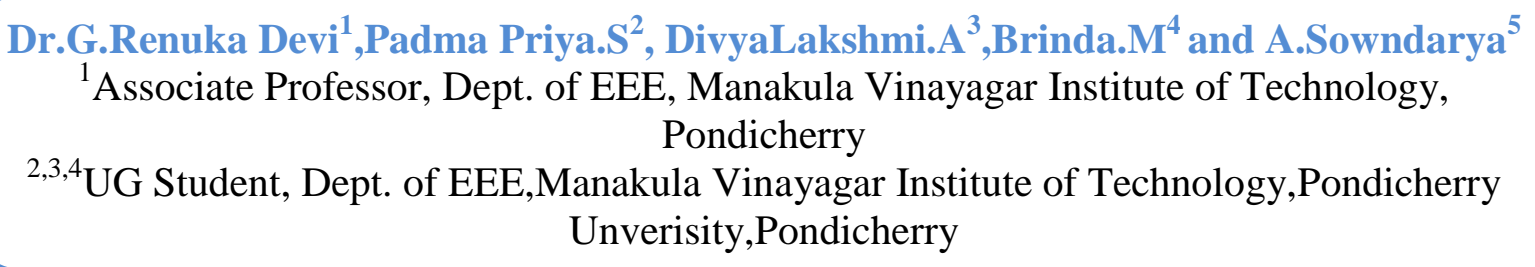

\section{ABSTRACT}

Energy is one of the major supplements for the economic growth of any country. In the case of the developing countries like India, the energy sector assumes a vital importance in increasing the energy needs that requires huge investments to meet them. Now a day's India is facing a lack of Electrical power availability. On the energy demand and supply side, India is facing a severe shortage. For reducing cost and increasing efficiency, then use energy conservation, management, and audit. The objective of Energy Management is to achieve and maintain optimum energy acquirement and utilization, throughout the organization in order to minimize energy costs/waste without affecting production and quality and also to minimize environmental effects. Energy Audit is the key to an organized approach for answerable in the area of energy management. This paper discusses the common aspects of electrical energy management and various phase of Energy audit to reduce energy requirements and hence, the total cost spent on energy consumption.

Key words: Energy Audit, Energy Management, Energy Conservation, Energy Savings, Power scenario of India.

Corresponding Author: Dr.G.Renuka Devi

\section{INTRODUCTION}

Energy is the ability to do work. It is the power derived from utilization of physical or chemical resources especially to provide heat or light or to work machines. The best energy management starts with an energy audit. An energy audit identifies where and how much energy is consumed in an existing facility, building or structure. It specifies the energy usage according to its distinct functions. In this paper we study energy management, energy conservation and energy efficiency by how to reduce energy demand to reasonable minimum Cost, recover and re-use heat where possible and also study use of energy efficient equipment to supply remaining energy demand, and provide a means to manage use of energy and also study energy and environment and study how to carry out energy audit.While the overall concept is similar to a home or residential energy audit, industrial energy audits require a different skill set. Weather proofing and insulating a house are the main focus of residential energy audits. For industrial applications, weather proofing and insulating often are minor concerns. In industrial energy audits, it is the HVAC, lighting, and production equipment that use the most energy.[1]

\section{POWER SCENARIO OF INDIA}

From the Independence, with the growth of an economy, India's power requirement has grown substantially. Our country today faces a peak shortage of power around 11- 18\% and an energy shortage of about 7-11\%[2]. Projected economic growth of India will 
necessitate corresponding growth in power requirement. In India, different sectors of electric energy consumption are as follows,

\begin{tabular}{|c|l|l|}
\hline Sl.No & \multicolumn{1}{|c|}{ Different sectors } & Percentage of Energy consumption \\
\hline 1 & Industrial & $26.64 \%$ \\
\hline 2 & Domestic and commercial & $30.78 \%$ \\
\hline 3 & Agriculture & $1.66 \%$ \\
\hline 4 & Transport & $29.35 \%$ \\
\hline 5 & Others & $11.57 \%$ \\
\hline
\end{tabular}

As of March 2015, the installed capacity of the electrical sector in India is around $271.722 \mathrm{GW}$. In the year 2014-15, it was $1010 \mathrm{kWh}$, the per capita electricity consumption in India with a total electricity consumption of 938.823 billion kWh. Among all countries, in 2014-15 India is the highest recorded of about $18.45 \%$ in the Electric energy consumption in the agriculture sector.

Table -1: All India Installed Capacity in (MW) of Power[2]

\begin{tabular}{|l|l|l|l|l|}
\hline \multirow{2}{*}{ Region } & \multicolumn{2}{c|}{ ENERGY } & \multicolumn{1}{c|}{ PEAK POWER } \\
\cline { 2 - 5 } & Requirement & Availability & Demand & supply \\
\hline Northern & 355,794 & 354,540 & 54,329 & 54,137 \\
\hline Western & 353,068 & 364,826 & 48,479 & 50,254 \\
\hline Southern & 313,248 & 277,979 & 43,630 & 35,011 \\
\hline Eastern & 124,610 & 127,066 & 18,507 & 19,358 \\
\hline North-Eastern & 15,703 & 13,934 & 2,650 & 2,544 \\
\hline All India & $1,162,423$ & $1,138,346$ & 156,862 & 152,754 \\
\hline
\end{tabular}

Before 2017, India required135 GW of power generation capacity. In the next ten years, India's power demand is expected to cross $300 \mathrm{GW}$.

To meet this demand India needs five to ten times to increase in the pace of capacity addition, the profile of planned capacities will also need to be suitably modified to fulfill peak demands.

A new radically approach of Energy Audit and conservation in any respect levels of electricity utilization is needed.

To fulfill the required power requirement of 315 to $335 \mathrm{GW}$ by 2017 , India requires a generation capacity of 415 to $440 \mathrm{GW}$. This implies a multiplication of putting in capability from the present level of regarding a hundred and forty $\mathrm{GW}$, which, in turn, interprets into Associate in Nursing annual addition of twenty to forty GW.

This is fivefold to tenfold the $4 \mathrm{GW}$ per year that was achieved in the last 10 years.[2]

\section{ENERGY MANAGEMENT}

"The strategy of adjusting and optimizing energy, exploitation systems, and procedures thus on scale back energy necessities per unit of output whereas holding constant or reducing total prices of manufacturing the output from these systems"[2].

\subsection{Objective of Energy Management:}

- To decrease the energy costs/waste.

- To minimize environmental effects [2].

\section{ENERGY AUDIT}

As per the Energy Conservation Act, 2001, Energy Audit is defined as "the verification, monitoring, and analysis of the use of energy including submission of a technical report 
containing recommendations for improving energy efficiency with cost benefit Associate in Nursingalysis and an action decide to scale back energy consumption".[3].

\subsection{Need for Energy Audit:}

In an industry, the most of the operating expenses are energy (both electrical and thermal), labor and materials. If one were to relate to the manageability of the cost or potential cost savings in each of the above components, energy would invariably emerge as a topranked,and so energy management operate constitutes a strategic space for the price reduction.Energy Audit can facilitate to grasp additional regarding the ways that energy and fuel area unit utilized in any business and help in identifying the areas where waste can occur andwhere scope for improvement exists.The Energy Audit would provide a positive orientation to the energy price reduction, preventive maintenance, and quality control programmes which are vital for production and utility activities.Such Associate in Nursing plan can facilitate to stay specialize in variations that occur within the energy prices, availability and reliability of supply of energy, decide on appropriate energy mix,identify energy conservation technologies, retrofit for energy conservation equipment etc.

In general, Energy Audit is the translation of conservation ideas into realities, by lending technically feasible solutions with economic and other organizational considerations within a specified time frame [2].

\subsection{Primary objective of Energy Audit:}

- To determine ways that to cut back energy consumption per unit of product output or to lower operative prices.

- Energy Audit provides a " benchmark" (Reference point) for managing energy within the organization and

- It also provides the premise for designing a more practical use of energy throughout the organization [3].

\subsection{Types of Energy Audit:}

The type of Energy Audit to be performed depends on:

- Function and kind of business

- Depth to which final audit is needed, and

- Potential and magnitude of cost reduction desired

Thus Energy Audit is often classified into [1]:

i) Preliminary Audit

ii) Detailed Audit

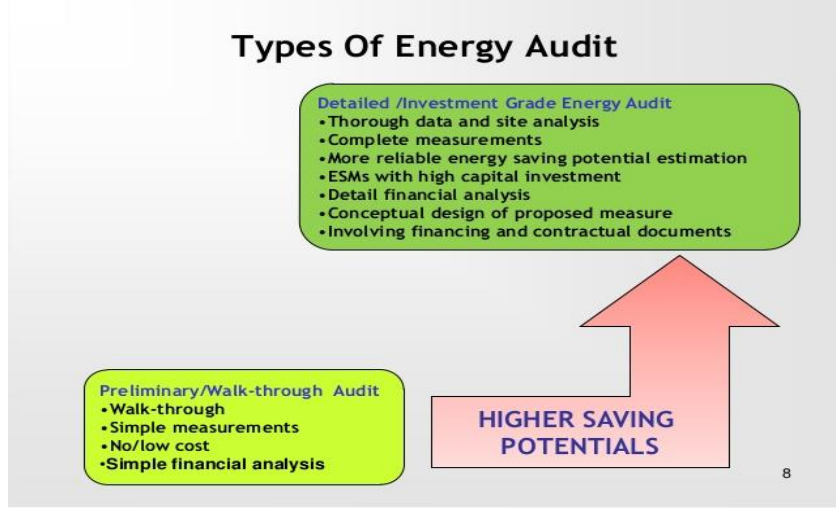

Fig-1:Types of Energy Audit 


\subsubsection{Preliminary Energy Audit Methodology}

- Establish energy consumption in the organization

- Estimate the scope for saving

- Identify the foremost probably (and the simplest areas for attention

- Identify immediate (especially no-/low-cost) improvements/ savings

- Set a 'reference point'

- Identify areas for more detailed study/measurement

- Preliminary energy audit uses existing, or simply obtained data [4].

\subsubsection{Detailed Energy Audit Methodology}

A comprehensive audit provides an in depth energy project implementation arrange for a facility, since it evaluates all major energy exploitation systems. This type of audit offers the foremost correct estimate of energy savings and value.It considers the interactive effects of all comes, accounts for the energy use of all major instrumentation, and includes careful energy value saving calculations and project value. In a comprehensive audit, one in every of the key components is that the energy balance.This is supported a listing of energy exploitation systems, assumptions of current in operation conditions and calculations of energy use.This calculable use is then compared to utility bill charges[5].Detailed energy auditing is applied in 3 phases:

- PhaseI-PreAuditPhase

- PhaseII-AuditPhase

- $\quad$ Phase III-Post Audit Phase

The methodology of Energy Audits needs to be flexible. A comprehensive ten-step methodology for conduct of Energy Audit at field level is presented below. Energy Manager and Energy Auditor may follow these steps to start with and add/change as per their needs and industry type.

\begin{tabular}{|c|l|l|}
\hline $\begin{array}{c}\text { STEP } \\
\text { NO: }\end{array}$ & \multicolumn{1}{|c|}{ PLAN OF ACTION } & \multicolumn{1}{c|}{ PURPOSE/RESULT } \\
\hline 1 & $\begin{array}{l}\text { PHASE 1: } \\
\text { Pre-Audit Phase } \\
\text { Planning and organizing } \\
\text { - Audit walk through } \\
\bullet \begin{array}{l}\text { Interview with energy manager, } \\
\text { Plant manager informally. }\end{array}\end{array}$ & $\begin{array}{l}\bullet \text { Planning of resource } \\
\bullet \text { Forming of energy audit team } \\
\bullet \text { Instruments and time frame organizing } \\
\bullet \text { Collection of macro data } \\
\bullet \text { Familiarizing about plant activities } \\
\bullet \text { Observing current operation activities }\end{array}$ \\
\hline 2 & $\begin{array}{l}\text { Conducting a brief meeting with } \\
\text { heads and concerned person }\end{array}$ & $\begin{array}{l}\bullet \text { Cooperation build up and awareness creation } \\
\text { Questioning of issues in ins } \\
\text { departments. }\end{array}$ \\
\hline
\end{tabular}




\begin{tabular}{|c|c|c|}
\hline 3 & 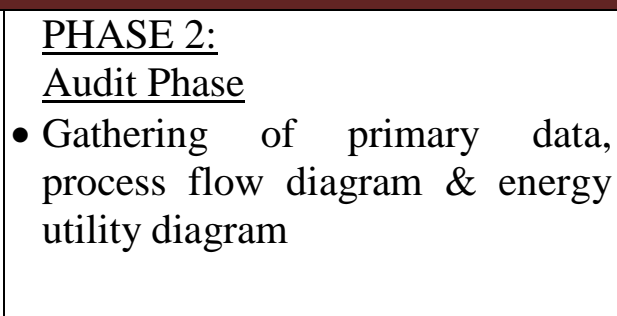 & $\begin{array}{l}\text { - Analyzing previous data and creating new } \\
\text { data } \\
\text { - Preparation of flow chart } \\
\text { And all utility diagrams } \\
\text { - Scheduling of operating data and design } \\
\text { - Creating annual energy bill \& consumption }\end{array}$ \\
\hline 4 & $\begin{array}{c}\text { - Conduction of survey and } \\
\text { monitoring }\end{array}$ & $\begin{array}{l}\text { - Measuring of: } \\
\text { Motor survey, } \\
\text { insulation, } \\
\text { lighting survey with portable instruments. }\end{array}$ \\
\hline 5 & $\begin{array}{l}\text { - Conduction of detailed trials for } \\
\text { selected energy guzzlers }\end{array}$ & $\begin{array}{l}\text { - Trials done for } 24 \text { hours power monitoring, } \\
\text { load variations trend in pumps, fanetc. } \\
\text { - Boiler and furnace efficiency trials for } 4-8 \\
\text { hours }\end{array}$ \\
\hline 6 & - Energy use analysis & $\begin{array}{l}\text { - Energy loss analysis } \\
\text { - Balancing of energy and material }\end{array}$ \\
\hline 7 & $\begin{array}{l}\text { - Identification and development of } \\
\text { energy conservation opportunities } \\
\text { (ENCON) }\end{array}$ & $\begin{array}{l}\text { - ENCON measures identification } \\
\text { - Collecting and developing refine ideas } \\
\text { - Review the previous ideas suggested by unit } \\
\text { personnel and energy audit } \\
\text { - Using brilliant value analysis techniques }\end{array}$ \\
\hline 8 & - Analysis of cost benefit & $\begin{array}{l}\text { - Selection of good projects } \\
\text { - Assessing technical feasibility, economic } \\
\text { viability of ENCON } \\
\text { - Prioritize from low to long term measures }\end{array}$ \\
\hline 9 & $\begin{array}{l}\text { - Top management reporting and } \\
\text { presentation }\end{array}$ & $\begin{array}{l}\text { - Documentation and report submission of top } \\
\text { management }\end{array}$ \\
\hline 10 & 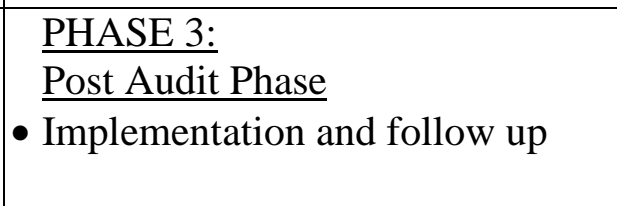 & $\begin{array}{l}\text { - Implement ENCON measures and monitor } \\
\text { procedures as recommended } \\
\text { - Action plan, scheduling followed by periodic } \\
\text { review }\end{array}$ \\
\hline
\end{tabular}

\subsubsection{Phase I -Pre Audit Phase Activities}

An organized procedure to carry out an energy audit is necessary for economical working. A basic study of the site should always be carried out, as the planning of the procedures necessary for an audit is most important [5].

\subsubsection{Initial Site Visit and Preparation Required for Detailed Auditing:}

- Discussion with the site's senior management about the aim of the energy audit.

- Review about economic guidelines associated with the suggestions of the audit.

- Analyse the major energy consumption data with the appropiate personnel. 
- Obtain site drawings, building layout, steam distribution, compressed air distribution, electricity distribution etc.

- Tourthe site accompanied by engineering/production.

\subsubsection{The main aims of this visit:}

- To identify the main energy consuming areas/plant items to be surveyed during The information to be collected during the detailed audit includes :

- Energy consumption by kind of energy, by a department, by major things of method equipment, by end-use a pair of.

- Material balance information (raw materials, intermediate and final merchandise, recycled materials, use of scrap or waste products, production of by-products for reuse in other industries, etc.)

- Energy cost and tariff data

- Process and material flow diagrams

- Generation and distribution of website services (eg.compressed air, steam).

- Sources of energy supply (e.g. electricity from the grid or self-generation)

- Potential for fuel substitution, process modifications, and the use of co-generation systems (combined heat and power generation).

- Energy Management procedures and energy awareness coaching programs inside the institution.

- Existing baseline information and reports are useful to get consumption pattern, production cost audit[5].

- To identify any existing instrumentation/ additional metering required.

- To decide whether any meters will have to be installed prior to the audit eg. $\mathrm{kWh}$, steam, oil or gas meters.

- To identify the instrumentation required for carrying out the audit.

- To plan with time frame

- To collect macro data on plant energy resources, major energy consuming centers

- To create awareness through meetings/ programme.

\subsubsection{Phase II- Detailed Energy Audit Activities}

Depending on the character and complexness of the positioning, a comprehensive audit will take from many weeks to many months to finish.Detailed studies to ascertain, and investigate energy and material balances for specific plant departments or things of method instrumentation area unit allotted.Whenever attainable, checks of plant operations area unit allotted over extended periods of your time, at nights and at weekends in addition as throughout traditional daytime operating hours, to ensure that nothing is overlooked.The audit report can embrace an outline of energy inputs and products outputs by the major department or by major process perform and can measure the potency of every stepof the manufacturing process.Means of up these efficiencies are listed, and a minimum of a preliminary assessment of the price of the enhancements are created to point the expected payback onany capital investment needed. The audit report should conclude with specific recommendations for detailed engineering studies and feasibility analyses, which must then be performed to justify the implementation of those conservation measures that require investments [6]

\subsubsection{The information to be collected during the detailed audit includes:}

- Energy consumption by a variety of energy, by the department, by major things of method equipment, by end-use. 
- Material balance information (raw materials, intermediate and final product, recycled materials, use of scrap or wasteproduct, production of by-products for re-use in different industries, etc.)

- Energy price and tariff information

- Method and material flow diagrams

- Generation and distribution of website services (eg.compressed air, steam).

- Sources of energy offer (e.g. electricity from the grid or self-generation)

- Potential for fuel substitution, method modifications, and also the use of co-generation systems (combined heat and power generation).

- Energy Management procedures and energy awareness coaching programs among the institution.

- Existing baseline info and reports square measure helpful to induce consumption pattern, cost and productivity levels in terms of product per staple inputs.

\subsubsection{The audit team ought to collect the subsequent baseline data [6]:}

- Technology, processes used and instrumentation details

- Capability use

- Quantity input materials used -

- Water consumption

- Fuel Consumption

- Current consumption

- Steam consumption

- Other inputs like compressed gas, cooling water etc

- Quantity wastes generated

- Share rejection / reprocessing

- Efficiencies/yield

\section{ENERGY AUDIT ON VARIOUS STATES OF INDIA}

\subsection{Kerala:}

- Kerala was way ahead of the times - it constituted its SDA, the Energy Management Centre, as anautonomous body in 1996, even before the country enacted the Energy Conservation Act.

- For this first index, only Kerala (and Punjab) were able to provide energy intensity for commercial and residential buildings for the entire state.

- In DISCOMS, Kerala has the lowest T\&D losses.

- In Ministry of Micro, Small and Medium Enterprises (MSME), though no state was able to furnish data on energy savings specifically in the MSME sector, Kerala provides technical and financial support for energy audits in MSME, as well as training for specific clusters.

- A best practice to be highlighted here is in the Pilicode gram panchayat in Kerala, which resulted in a bimonthly reduction of 1,20,328 units power consumption. This was made possible by a team of 650 volunteers, trained in energy conservation, who created awareness in households on energy conservation, power consumption of various types of lighting and appliances. The strategy included What Sapp, government directions, subsidised LED bulbs and five-star rated fans to replace existing ones in streets and government buildings.

\subsection{Rajasthan}

- Rajasthan was among the four states that provided data on energy savings in the industrial sector as a whole. 
- In MSME, Rajasthan has implemented fuel saving projects in five small scale industries.

- Rajasthan's State Road Transportation Corporation has among the best performance for energy intensity.

- In DISCOMS, it is among the states with the most DSM regulations and program me in place.

\subsection{Andhra Pradesh}

- Andhra's SDA is the only SDA in the country whose sole mandate is to promote energy efficiency. Most other SDAs have energy efficiency as an additional responsibility, which can digress to the mainstream functioning of the parent department.

- In buildings, Andhra Pradesh was the first state to incorporate ECBC in municipal building bye-laws.

- In the MSME sector, Andhra Pradesh has conducted workshops for clay brick cluster and ice-making cluster.

- In transport, not only does Andhra Pradesh have among the best performance for energy intensity of the State Road Transportation Corporation (SRTC), it also has amongst the most fuel-efficient SRTCs, and is among states that provide financial incentives for electric and hybrid vehicles.

- The state's DISCOMS are among those with most DSM regulations and program me in place [7].

\subsection{Maharashtra}

- Maharashtra Energy Conservation Policy, 2016 - adopted by Maharashtra's SDA - has been recommended by the AEEE report to be adopted by all current SDAs, to lay down a charter for policies and programmes pertaining to energy efficiency.

- In buildings, Maharashtra leads in terms of penetration of green buildings and BEE starrated buildings, with BEE star appliances for all public buildings being made mandatory.

- In industry, Maharashtra and Tamil Nadu are the only states to have set energy saving targets for industry, apart from targets set for the PAT program me.

- In MSMEs, Maharashtra has a cluster development program me, which includes energy audits, workshops and demonstration projects.

- Under Municipality, the Maharashtra Energy Conservation Policy, 2017 has several good measures - schemes in street lighting and water pumping, for municipal corporations, councils, MIDC, etc, many of which are being adopted by MEDA.

- In transport, Maharashtra's 'Electric Vehicle Policy 2018' provides for incentives and subsidies for EV manufacturing, charging infrastructure and EV ownership.

- Nagpur is the first city in India to have an electric mass mobility system, with Ola managing a fleet of 200 electric taxis, buses and rickshaws [7].

\subsection{Punjab}

- In buildings, Punjab has in place energy intensity provisions for commercial and residential buildings for the entire state.

- Many frontrunner states provide financial incentives for ECBC-compliant construction and retrofits, but Punjab additionally gives 15 per cent rebate in property tax.

- For this first Index, only Kerala and Punjab were able to provide energy intensity for commercial and residential buildings for the entire state.

- The Punjab government has also notified 'The Punjab Municipal Green Buildings Incentives Policy-2016', with a host of incentives for energy-efficient green buildings.

- In Industry, 80 per cent or more DCs met the SEC target in PAT Cycle. 
- Punjab was one of the four states that provided data on energy savings in the industrial sector as a whole

- The state also provides technical and financial support for energy audits in MSME[7].

- Punjab has implemented projects with Revolving Investment Fund (RIF) mechanism from its SECF (State Energy Conservation Fund).

\subsection{Uttar Pradesh}

Under the Uttar Pradesh Kisan UDAY Yojana 2018, the government has begun distributing BEE 5-star rated energy-efficient pumps to 10 lakh farmers in the state, to replace the existing inefficient pumps and save approximately 3.5 billion units of electricity and Rs 1,350 crore every year. Uttar Pradesh also has 80 per cent or more designated consumers (DCs) meeting the specific energy consumption (SEC) target in PAT Cycle I.

\subsection{Karnataka}

It is a front-runner in electric mobility, with its 'Karnataka Electric Vehicle and Energy Storage Policy 2017' providing incentives and concessions for the e-mobility eco-system [7].

\subsection{Meghalaya}

- It is the leader in EVs, with the highest proportion of EV's (via the FAME scheme), and Delhi, Gujarat, Haryana, and Uttarakhand follow.

- Then, Karnataka, Odisha, Punjab and Uttarakhand have implemented projects with something called Revolving Investment Fund (RIF) mechanism from their State Energy Conservation Fund.

- Goa, Meghalaya and Uttarakhand lead the PAT, with 100 per cent DCs in these states meeting the SEC target in PAT Cycle I.

\section{Conclusion}

This paper solves some light on the way of energy generation through energy conservation by means of Energy Audits. To reduce energy exportation of their growing and developing economy and need renewable energy capacity addition targets. India has sufficient potential of renewable energy but combination of correct human behavior and right technology is needed because every technology have their own limitation, then having peoples readiness to accept of Renewable Energy.India will can be use many of these tools innovatively to achieve an imposing growth in its Renewable Energy sector with a high impact on the ground (green power generation) and a low dependency upon financial support.

\section{References}

1.Preliminary electrical energy audit analysis of mineral based industry Prasad Bhukya*Academy of Scientific and Innovative Research, CSIR Central Institute of Mining and Fuel Research, Dhanbad, India.

2.Sachin P. Partheland Santosh Kompeli, "Energy Audit and Conservation Tool for Energy Efficiency" International Research Journal of Engineering and Technology (IRJET), Volume: 02 Issue: 08, Nov-2015.

3.https://www.beeindia.gov.in/.

4.http://en.wikipedia.org/wiki/Energy_audit

5.https://swarajyamag.com/

6.https://mnre.gov.in/

7.Farzaneh Haghighat Nia, Hossein Niavand, “ Impact of Renewable Energy Consumption on Economics in India "International Journal of Energy Engineering,do10.5923/j.ijee.20170701.03. 